\title{
Н.В. Южанин
}

\section{САМОЗАЩИТА ГРАЖДАНСКИХ ПРАВ И МЕРЫ ОТВЕТСТВЕННОСТИ}

\begin{abstract}
В статье рассматриваются понятие самозащиты и механизм ее реализации в гражданском праве отраслевыми односторонними правозащитными мерами. Рассматривается соотношение понятия «односторонние правозащитные меры» с понятиями «меры защчиты», «способы защчиты». Анализируется соотношение понятия «односторонние правозащитные меры» с понятиями «юридическая ответственность», «санкции». Обосновывается единство правовой природы всех односторонних мер зацииты гражданских прав.

Ключевые слова: защита прав, самозащита прав, меры ответственности, меры зацииты, ответственность, санкции, односторонние правозащитные меры, меры оперативного воздействия, удержание, правоохранительные меры, охранительное правоотномение.
\end{abstract}

В условиях современного развития частного права особую актуальность приобретает вопрос о защите гражданских прав мерами самостоятельного, одностороннего характера, поскольку специфика частных правоотношений предполагает наличие особых отраслевых мер самостоятельного противодействия различным посягательствам на субъективные права. В настоящее время самозащита закрепляется в законе как способ пресечения нарушения прав (ст. 14 ГК РФ), однако в пандектной системе права существовали и существуют меры самозащиты не только пресекательного, но и восстановительного характера ${ }^{1}$, что подчеркивает возможность существования самозащиты как способа восстановления нарушенных прав. Полагаем, что самозащита - это форма защиты, реализующаяся в основном способом пресечения нарушения, а иногда и способом их восстановления при допустимости законом. В рамках формы самозащиты существуют отраслевые односторонние меры защиты (односторонние правозащитные меры).

Первичная функциональная цель защиты права - это пресечение нарушения или угрозы нарушения субъективных прав. Восстановление прав - это также результат дальнейшей реализации правоохранительного механизма, который, как правило, связан с государственно-властным участием. Восстановительная (компенсационная) функция присуща и гражданско-правовой ответственности. В теории гражданского права справедливо возникает вопрос: как соотносятся понятия «меры защиты», особенно в договорных правоотношениях, с «мерами ответственности», «санкциями». Актуален этот вопрос и в связи с тем, что в цивилистике самостоятельные, односторонние

\footnotetext{
1 Задержание вещи в закладе, восстановительная самопомощь посредством отобрания вещей из владения нарушителя (право кулака) восстанавливают нарушенные права односторонними действиями защищающегося.
} 
правозащитные меры в договорных правоотношениях часто именуются оперативными санкциями. Полагаем, что меры самозащиты в договорных правоотношениях имеют единую правовую природу с мерами самозащиты внедоговорного применения. Поэтому необходимо ответить на вопрос: как соотносятся все подобные односторонние правозащитные меры с понятием мер ответственности, санкциями?

Односторонние правозащитные меры относятся к широкому понятию гражданско-правовой защиты. Защита гражданских прав функционально направлена не только на пресечение нарушения или его угрозы, но и на восстановление уже нарушенных прав, поэтому широкое понятие защиты прав включает в себя также и понятие гражданско-правовой ответственности, поскольку ей присущ восстановительный (компенсационный) характер. Применение мер ответственности связано и с фактом нарушения обязанностей (возмещение убытков).

В узком смысле конкретные меры защиты не тождественны мерам ответственности, хотя бы потому, что первые могут реализовываться субъектами гражданских правоотношений односторонне и самостоятельно, т.е. без государственно-властного участия, а также не предполагают какихлибо дополнительных обременений для конкретного нарушителя. Таким образом, субъекты гражданских правоотношений могут самостоятельно применять в рамках материального правоотношения только такие односторонние меры защиты, которые не связанны с гражданско-правовой ответственностью. В ретроспективном аспекте гражданско-правовая ответственность реализуется исключительно государственно-принудительно. Поэтому меры гражданско-правовой ответственности всегда связаны с другой стороной правоотношения, правонарушителем. Меры же гражданско-правовой защиты могут применяться и при отсутствии конкретного правонарушения, они могут вовсе не быть связанными с санкциями и неблагоприятными последствиями для конкретного нарушителя. Конкретный нарушитель может вообще отсутствовать, поскольку факт нарушения права не всегда связан с действием какого-то субъекта. Источником нарушения субъективных прав могут являться различные источники опасности, не только противоправные действия человека.

Судебные и иные государственные юрисдикционные органы при осуществлении правоохранительной деятельности вправе применять в отличие от субъектов частноправовых отношений меры гражданско-правовой ответственности. Речь идет о ретроспективном аспекте ответственности. Восстановление нарушенного права чаще всего может осуществиться посредством обременения конкретного нарушителя, который обязан возместить, компенсировать, т.е. восстановить нарушенное. В ретроспективном аспекте восстановление нарушенной сферы потерпевшего осуществляется государственно-принудительно, на конкретного нарушителя возлагается обязанность осуществления восстановительных (компенсационных) действий и обеспечивается такая обязанность всей мощью государственного аппарата. В перспективном же аспекте можно говорить об ответственности, которую несут все юридически обязанные субъекты. Перспективная ответственность существует вне государственного принуждения [1. С. 76]. Таким образом, понятие 
«ответственность» в праве шире понятия «меры ответственности». Его нельзя сводить только лишь к невыгодным имущественным последствиям, ограничениям личного и имущественного характера, мерам или формам принуждения. Во всех перечисленных элементах речь идет о наказательном аспекте ответственности, или по-другому о ретроспективном.

Не следует рассматривать ответственность и как охранительное правоотношение, поскольку ответственность не возникает исключительно в самостоятельных правоотношениях охранительного содержания, а является внутренним элементом любого гражданского правоотношения как ненарушенного в форме заранее установленных нормативно или договорным порядком возможно применимых мер ответственности, или конкретно реализуемых мер в случае совершения правонарушения [1. С. 66]. Таким образом, ответственность триедина. Во-первых, она состоит в возможности ее наступления только лишь с появлением гражданского правоотношения и субъективными обязанностями в его рамках. Назовем такое проявление ответственности как возможность ее наступления. Во-вторых, она возникает по факту юридического основания (правонарушения) как в правоотношении, в котором произошло нарушение, так и в отдельном охранительном правоотношении (деликтное обязательство). В-третьих, должна присутствовать государственнопринудительная реализация ответственности.

Итак, восстановление права чаще всего реализуется государственнопринудительно и связано с деятельностью конкретно обязанного к этому субъекта - правонарушителя, поэтому оно чаще всего реализуется за счет и посредством действий самого нарушителя. Пресечение же нарушения возможно и односторонними оперативными и самостоятельными действиями самого потерпевшего или третьих лиц, а не только посредством обращения к аппарату государственного принуждения. Реализация пресекательных мер защиты может быть как при посредстве принудительной деятельности государства, так и оперативной односторонней и допустимой законом понудительно-принудительной деятельности самого управомоченного лица без обращения к компетентным государственным или общественным органам. Защита права посредством пресечения нарушения может произойти в рамках материального правоотношения без участия органов государства. В некоторых случаях допустимо, когда право предоставляет возможность совершать восстановление прав односторонним и самостоятельным порядком. Это исключительные меры, но они возможны в условиях развитого частноправового регулирования. Восстановление прав посредством самозащиты является максимальным проявлением государственного доверия частноправовому началу. Таким образом, самозащита и юрисдикционная защита в совокупности обеспечивают как пресечение нарушения, так и восстановление прав, но принудительный механизм реализации конечной функциональной цели защиты прав - их восстановление посредством наложения мер ответственности принадлежит только государству.

Понятие «меры защиты» наиболее часто ассоциируется со «способом защиты» права. Оно часто отождествляется также и с такими понятиями, как средства, способы принуждения обязанного субъекта (должника) для достижения целей правовой защиты [2. С. 16]. Мера защиты у́же понятия способа 
защиты, но может целиком совпадать с ним, когда лишь одним правозащитным действием, т.е. мерой, достигается функциональная цель защиты - пресечение или восстановление нарушенных прав. Когда речь идет об особых односторонних правозащитных мерах, то они являются лишь частью единого понятия «меры защиты», которое объединяет в себе меры государственновластного принуждения и дозволенные самостоятельные действия - отраслевые односторонние меры защиты субъективных прав, реализуемые в рамках самостоятельной формы защиты прав. Все односторонние правозащитные меры в механизме гражданско-правового регулирования общественных отношений реализуют правомочие на защиту в рамках субъективного права. Любое одностороннее действие субъекта гражданского права в обязательстве или в рамках абсолютного правоотношения, направленное на предотвращение нарушения или его угрозы, является мерой защиты субъективного гражданского права.

По рассматриваемому вопросу мэтр отечественной теории права С.С. Алексеев обращает внимание на следующее: необходимо отграничить меры, направленные на восстановление нарушенных прав потерпевшего, т.е. меры защиты, от иных мер, например, от мер гражданско-правовой ответственности, поскольку реализация первых не приводит к формированию дополнительных обременений для лища, нарушившего чужое право, а последние предполагают возложение на правонарушителя новых обременяющих обязательств. В отличие от мер гражданско-правовой ответственности меры защитты субъективных гражданских прав обеспечивают их восстановление и при отсутствии вины правонарушителя [3. С. 184-189]. Представленные признаки различий между мерами защиты и мерами ответственности действительно обнаруживают разность между ними, хотя они и осуществляются в едином правоохранительном механизме и реализуют охранительную функцию гражданского права. Действительно, например, односторонним порядком, т.е. самостоятельно, возможно пресечь нарушение и реализовать защиту, но нельзя установить дополнительное обременение для нарушителя. Это же касается и возможности применения защиты, которая совершенно может не касаться какого-то виновного поведения конкретного лица, но применять к нему меры принуждения. Обороняющийся от посягательства невменяемого лица защитительно применяет к нему меры принуждения, т.е. реализует защиту права. Однако невменяемый не виновен, с юридической точки зрения он не может быть правонарушителем. Это же касается и случаев устранения опасности от нападения животного, т.е. крайней необходимости, и др. Таким образом, меры защитты в узком смысле не тождественны мерам гражданско-правовой ответственности.

Меры защиты гражданских прав хотя и реализуются во многих случаях самостоятельно и по желанию самого потерпевшего, но требуют часто юрисдикционного соучастия. В гражданском праве существует весомый спектр мер защиты, требующих юрисдикционного вмешательства, т.е. государственно-принудительного. Например, компенсация морального вреда может произойти только посредством судебного присуждения выплаты денежной компенсации, такой же характер носит присуждение к исполнению обязанности в натуре. Меры же реализации защитительного правомочия субъективно- 
го права, которые являются вариантом проявления исключительно односторонней воли без посредства юрисдикционного органа, характеризуются внутривидовой общностью, которая позволяет рассматривать их как самостоятельные правозащитные действия в правоохранительном механизме, а соответственно и в механизме гражданско-правового регулирования общественных отношений. В рамках односторонних правозащитных мер можно выделить меры оперативного воздействия в договорных правоотношениях. Давний спор возник в вопросе отнесения мер оперативного воздействия к понятиям «меры ответственности» и «санкции». Поскольку такие меры являются частью единого понятия односторонних правозащитных мер в гражданском праве, то логично коснуться некоторых аспектов этой дискуссии.

Все односторонние правозащитные меры в гражданском праве характеризуются общностью, которая позволяет рассматривать их как самостоятельные юридические действия в гражданском праве, со своей спецификой и механизмом применения. Безусловно, внутри этого юридического понятия можно выделить и некоторые меры, характеризующиеся также незначительной спецификой (в силу специфики самого правоотношения организационнопреобразовательного характера), к таковым и относятся меры оперативного воздействия, которые применяются исключительно в договорных правоотношениях. Однако не следует придавать столь существенное значение их особенности лишь по тому факту, что они урегулированы законом. На момент применения подобных мер характер нарушения прав, соответственно и возможность их применения, защищающийся оценивает субъективно, точно так же, как и в момент применения односторонних правозащитных мер во внедоговорном правоотношении. В договорном правоотношении меры защиты направлены против контрагента нарушителя, который естественным образом известен защищающемуся, а во внедоговорном правоотношении нарушитель может быть не только не известен, но и само нарушение субъективного права может быть вообще не связано с деятельностью субъекта прав, например, опасность может исходить от сил природы.

Что же касается гражданско-правовых санкций, то нередко это понятие ассоциируется с ответственностью. Это понятие в теории гражданского права также спорно. Под санкцией можно понимать как последствия, установленные правовой нормой за ее несоблюдение, так и конкретную меру воздействия, которая применяется к неисполняющим требования нормы субъектам. В гражданском праве фигурируют в основном компенсационные санкции, т.е. меры восстановительного характера. Также существуют санкции штрафного или конфискационного характера. Штрафной характер санкций свойствен тем ситуациям, когда взыскание осуществляется сверх восстановления. Конфискационный характер санкций связан с субъектом, в пользу которого происходит взыскание, когда речь идет о взыскании в доход государства. Корифей советской цивилистики С.Н. Братусь отмечает, что под санкцией нормы права могут пониматься любые правовые последствия правонарушения, предусмотренные законом для какого-то конкретного случая, в том числе и те, что не связаны с использованием силы государственного принуждения [4. C. 122]. При таком юридическом понятии санкции естественно, что применение всех односторонних правозащитных мер следует рассматривать как реа- 
лизацию гражданско-правовой санкции. Понятие же гражданско-правовой ответственности тесно связано с понятием санкции.

Не будем подробно вдаваться в эту давнюю дискуссию (о соотношении понятия юридической ответственности и санкций) в юридической литератуpe, приняв за основу одну из наиболее последовательных позиций по этому вопросу, а именно, что гражданско-правовая ответственность есть реализациия гражданско-правовой санкциии [5. С. 85; 6. С. 18] ${ }^{1}$. Таким образом, если взять за основу широкое понятие юридической санкции, которое обозначил С.Н. Братусь, мы приходим к выводу, что применение односторонних правозащитных мер - это реализация гражданско-правовой санкции, следовательно, и гражданско-правовой ответственности. Однако такое широкое понимание санкций предполагает наличие у всех санкций неких особо единых признаков. Если же проанализировать применение односторонних правозащитных мер, то они имеют как раз ряд существенных отличий от большинства «традиционных» санкций в гражданском праве, следовательно, подобный слишком широкий подход все-таки вряд ли оправдан. Так, при сравнительном анализе односторонних правозащитных мер в договорных обязательствах (оперативных мер) с понятием юридических санкций отмечаются такие отличия: 1) эти меры применяются управомоченным лицом независимо от вины нарушителя обязательства; 2) меры применяются управомоченным лицом самостоятельно, без участия арбитража, при этом подчеркивается наличие государственного принуждения, которое наступает не непосредственно, а благодаря возможности вмешательства арбитража или иного органа; 3) меры не выполняют компенсационной функции, поскольку не связаны с передачей денежных средств [7. С. 67] $]^{2}$.

Из представленных отличий особо следует обратить внимание на первое и существенное, заключающееся в том, что применение односторонних правозащитных оперативных мер не связано с выяснением виновности нарушителя, по крайней мере на момент применения такой меры. Оценка поведения нарушителя на момент правоприменения происходит исходя из самостоятельного, одностороннего и оперативного анализа ситуации. Защищающийся предполагает о наличии нарушения его субъективного права или существенной угрозы такого нарушения, что и является основанием к одностороннему противодействию посягательства на право. Установить четкие признаки совершаемого противоправного деяния со стороны хоть и известного нарушителя - контрагента - на момент применения односторонней правозащитной меры не представляется возможным. Однако условие правомерности применения защиты предполагает наличие нарушения права, а иначе это означало бы, что закон допускает защиту от правомерных действий, что абсурдно. Особенность нарушений прав в рамках договорных правоотношений связана с тем, что такое нарушение всегда обусловлено действием конкрет-

\footnotetext{
${ }^{1}$ О.Э. Лейст полагает, что ответственность - это применение и реализация санкции в случае правонарушения. Подобный взгляд на проблему проявляется и в современных работах. М.С. Карпов утверждает, что ответственность есть применение санкции, тогда как санкция есть та конкретная мера, которая применяется к правонарушителю.

${ }_{2}^{2}$ Автор анализирует признаки оперативных санкций (мер оперативного воздействия), которые, по нашему мнению, входят в общее понятие односторонних правозащитных мер.
} 
ного субъекта права - контрагента, тем не менее установить все признаки правонарушения в его поведении защищающийся не в силах, в любом случае его оценка субъективна. Объективную оценку посягательства как правонарушения может установить суд как основной юрисдикционный орган защиты прав.

Во внедоговорных правоотношениях нарушение субъективного права может быть и не связано с конкретным субъективным действием, но противодействие ему тоже является защитой субъективного права и она предполагает правомерное причинение вреда, например, третьим лицам (крайняя необходимость). Тем не менее и в этом случае защищающийся оценивает ситуацию с нарушением его прав субъективно. Следует также учитывать, что элемент вины в условиях наступления гражданской ответственности является специфическим, так как отсутствие вины в своих действиях доказывает ответственная сторона. Кроме того, в гражданском праве существует хоть и не бесспорное понятие «эвентуальная ответственность»- независимо от вины [8. С. 7]. На момент применения односторонней правозащитной меры произвести объективную оценку, а не субъективную (самим защищающимся) содеянного нарушителем не представляется возможным, поэтому субъект, защищающийся односторонним порядком, полагается только на внешнюю фактическую сторону произошедшего, ему достаточно лишь оперативно оценить ситуацию и сделать вывод о противоправности поведения контрагента. Главное, что есть все признаки нарушения и в некоторых случаях предполагаемого нарушения (существенная угроза) субъективным правам.

Таким образом, односторонние правозащитные меры как в договорных правоотношениях, так и во внедоговорных не являются мерами ответственности, санкциями. Если для оперативных правозащитных мер в рамках договорного правоотношения такой вопрос еще носил какой-то спорный характер, то для внедоговорных отношений вполне очевидно, что такие самостоятельные односторонние правозащитные действия никак не могут быть названы ни санкциями, ни мерами ответственности. Все односторонние правозащитные действия в гражданских правоотношениях являются специфическими отраслевыми мерами формы самозащиты - односторонними правозащзитныли мерами.

\section{Лuтература}

1. Тархов В.А. Гражданские права и ответственность. Уфа: УВШ МВД РФ, 1996. 124 с. $464 \mathrm{c}$.

2. Андреев Ю.Н. Механизм гражданско-правовой защиты. М.: Норма: Инфра-М, 2010.

3. Алексеев С.С. Право: азбука - теория - философия. Опыт комплексного исследования. М.: Статут, 1999. $712 \mathrm{c}$.

4. Братусь С.Н. Юридическая ответственность и законность. М.: Юрид. лит., 1976. 216 с.

5. Лейст О.Э. Санкции в советском праве. М.: Госюриздат, 1962. 238 с. $141 \mathrm{c}$.

6. Карпов М.С. Гражданско-правовые меры оперативного воздействия. М.: Статут, 2004.

7. Бриных E.B. Оперативные санкции - форма гражданско-правовой ответственности // Советское государство и право. 1969. № 6. С. 65-70. 
8. Андреев А.А. Эвентуальная ответственность в гражданском праве: автореф. дис. ... канд. юрид. наук. Рязань, 2011. 24 с.

Yuzhanin Nikolay Vyacheslavovich. DOI 10.17223/22253513/17/12

\section{SELF-DEFENSE OF CIVIL RIGHTS AND ACCOUNTABILITY MEASURES}

Key words: protection of rights, self-defense rights, accountability measures, protections, responsibilities, sanctions, unilateral measures of protection, measures operational impact, retention, law enforcement measures, protective legal relationship.

In the modern development of private law, especially important to the issue of protection of civil rights measures independent, one-sided, because the specifics of private relations requires a particular sectoral measures to counter various independent attacks on personal rights. Currently, self-defense enshrined in the law as a way to curb rights violations (Art. 14 of the Civil Code), but pandectists right to exist, and there are measures of self-defense is not only preclusive but reductive character, which emphasizes the possibility of the existence of self-defense as a means of redress, including in the domestic civil law. Self-defense is a form of protection is realized mainly way to prevent them, and sometimes the way to restore them if permitted by law. Within the industry, there are forms of self-defense unilateral protection measures (human rights unilateral action).

Unilateral measures relate human rights to a broad concept of civil protection, which also includes the concept of civil liability, because it is inherent in the recovery (compensation) character.

In a narrow sense, specific protection measures are not the same responsibility, not least because it can be implemented the first subjects of civil relations unilaterally and independently, that is, without the participation of public-powerful, and do not involve any additional charges for a particular offender. In a retrospective aspect of the civil liability of the state and sold exclusively by force. Therefore, measures of civil liability are always connected with the other party relationship, the offender. Measure the civil protection can also be used in the absence of a specific offense, they can not be associated with the adverse effects of sanctions and for a particular offender.

It should not be considered responsible as a protective legal relationship, because the responsibility does not arise solely in independent legal relationship of protective detention, and is an internal component of any civil legal relationship as the undisturbed in the form of predetermined regulatory or contractually possible applicable measures of responsibility or specific measures implemented in the case of the offense.

Self-protection and judicial protection in combination provide both prevention of violations and the restoration of rights, but the mechanism of forced implementation of the final functional aim of protecting the rights - to restore them by applying measures of responsibility belongs only to the state.

\section{References}

1. Tarkhov, V.A. (1996) Grazhdanskie prava i otvetstvennost' [Civil rights and responsibilities]. Ufa: Ministry of Interior of the Russian Federation.

2. Andreev, Yu.N. (2010) Mekhanizm grazhdansko-pravovoy zashchity [The mechanism of civil protection]. Moscow: Norma: Infra-M.

3. Alekseev, S.S. (1999) Pravo: azbuka - teoriya - filosofiya. Opyt kompleksnogo issledovaniya [The Law: the alphabeth - theory - philosophy. An experience of complex research]. Moscow: Statut.

4. Bratus, S.N. (1976) Yuridicheskaya otvetstvennost' i zakonnost' [Legal responsibility and legitimacy]. Moscow: Yuridicheskaya literatura. 
5. Leist, O.E. (1962) Sanktsii v sovetskom prave [Sanctions in the Soviet law]. Moscow: Gosyurizdat.

6. Karpov, M.S. (2004) Grazhdansko-pravovye mery operativnogo vozdeystviya [Civil measures of operational impact]. Moscow: Statut.

7. Brinykh, E.V. (1969) Operativnye sanktsii - forma grazhdansko-pravovoy otvetstvennosti [Operational sanctions as a form of civil liability]. Sovetskoe gosudarstvo i pravo. 6. pp. 65-70.

8. Andreev, A.A. (2011) Eventual'naya otvetstvennost' v grazhdanskom prave [Eventual liability in the civil law]. Abstract of Law Cand. Diss. Ryazan. 